(2)

OPEN ACCESS

\title{
Primary care-based smoking cessation treatment and subsequent healthcare service utilisation: a matched cohort study of smokers using linked administrative healthcare data
}

\author{
Dolly Baliunas (ㄷ) 1,2,3 Peter Selby (1) , 3,4,5,6 Claire de Oliveira (ㄷ) , 7,8,9,10 \\ Paul Kurdyak, ${ }^{5,9,10,11}$ Laura Rosella, ${ }^{3,9}$ Laurie Zawertailo (1) , ${ }^{4,12}$ Longdi Fu, ${ }^{9}$ \\ Rinku Sutradhar ${ }^{3,9,10,13}$
}

- Additional supplemental material is published online only. To view, please visit the journal online (http://dx.doi. org/10.1136/tobaccocontrol2021-056522).

For numbered affiliations see end of article.

\section{Correspondence to} Dr Dolly Baliunas, School of Public Health, The University of Queensland, Herston QLD 4072, Australia;

d.baliunas@uq.edu.au

Received 29 January 2021 Revised 10 April 2021 Accepted 27 April 2021
Check for updates

(C) Author(s) (or their employer(s)) 2021. Re-use permitted under CC BY-NC. No commercial re-use. See rights and permissions. Published by BMJ.

To cite: Baliunas D, Selby $P$, de Oliveira C, et al.

Tob Control Epub ahead of print: [please include Day

Month Year]. doi:10.1136/

tobaccocontrol-2021-056522

\begin{abstract}
Background No research has assessed the individual-level impact of smoking cessation treatment delivered within a general primary care patient population on multiple forms of subsequent healthcare service use.

Objective We aimed to compare the rate of outpatient visits, emergency department (ED) visits and hospitalisations during a 5-year follow-up period among smokers who had and had not accessed a smoking cessation treatment programme.

Methods The study was a retrospective matched cohort study using linked demographic and administrative healthcare databases in Ontario, Canada. 9951 patients who accessed smoking cessation services between July 2011 and December 2012 were matched to a smoker who did not access services, obtained from the Canadian Community Health Survey, using a combination of hard matching and propensity score matching. Outcomes were rates of healthcare service use from index date (programme enrolment or survey response) to March 2017.
\end{abstract}

Results After controlling for potential confounders, patients in the overall treatment cohort had modestly greater rates of the outcomes: outpatient visits (rate ratio (RR) $1.10,95 \% \mathrm{Cl}: 1.06$ to 1.14), ED visits (RR $1.08,95 \% \mathrm{Cl}: 1.03$ to 1.13 ) and hospitalisations (RR $1.09,95 \% \mathrm{Cl}: 1.02$ to 1.18). Effect modification of the association between smoking cessation treatment and healthcare service use by prevalent comorbidity was found for outpatient visits $(p=0.006)$, and hospitalisations $(p=0.050)$, but not ED visits. Conclusions Patients who enrolled in smoking cessation treatment offered through primary care clinics in Ontario displayed a modest but significantly greater rate of outpatient visits, ED visits and hospitalisations over a 5-year follow-up period.

\section{INTRODUCTION}

Worldwide, smoking remains a leading cause of premature death and disability ${ }^{1}$ and billions of dollars in lost productivity and healthcare resource use are related to smoking every year. ${ }^{12}$ To combat this burden, the WHO's Framework Convention on Tobacco Control (FCTC) recommends the provision of effective tobacco dependence treatment using existing healthcare infrastructure as much as possible; integrating cessation support into the primary healthcare system is an essential component of any tobacco control strategy. ${ }^{3}$ Almost all highincome countries make cessation services available with $90 \%$ offering at least partial cost coverage. ${ }^{3}$

There is a wealth of high quality research on the clinical effectiveness of smoking cessation treatment. ${ }^{4-6}$ Yet, the translation of clinical effectiveness of smoking cessation treatment on healthcare service use using real-world evidence has received limited attention in the literature. ${ }^{7}$

Prior research has largely focused on the effect of smoking cessation treatment provided to hospitalised patients on subsequent re-hospitalisation..$^{8-12}$ Overall, the evidence suggests that hospital-based cessation programmes can lower re-admission rates. ${ }^{13}$ This evidence is limited to the subpopulation of smokers accessing tertiary care due to significant existing comorbidities. To our knowledge, only one study has examined healthcare service use among a broad general patient base of smokers. ${ }^{14}$ Patients who accessed a smoking cessation pharmacotherapy benefit experienced a decrease in hospitalisations for acute myocardial infarction and atherosclerosis but not for other cause-specific diagnoses.

Chronic conditions that are more common among people who smoke, such as chronic obstructive pulmonary disease (COPD) and cardiovascular disease, are associated with increased levels of healthcare service use. ${ }^{15-19}$ Although quitting smoking has been shown to provide health benefits for these and other diseases, the degree of health benefits and period of abstinence over which they are observed is variable. ${ }^{20}$ As such, the impact on healthcare service use following smoking cessation treatment may vary between groups with different comorbidities.

No research to date has assessed the real world individual-level impact of smoking cessation treatment delivered within a general primary care patient population on multiple types of healthcare service use. Therefore, using linked administrative healthcare data, we compared outpatient visits, emergency department (ED) visits and hospitalisations among smokers who had and had not accessed a smoking cessation treatment programme, and interactions with prevalent comorbidities, in Ontario, Canada. 


\section{METHODS}

\section{Study design}

This retrospective matched cohort study used routinely collected smoking cessation treatment programme data linked to population-based administrative and demographic databases housed at ICES (https://www.ices.on.ca). ICES is an independent, non-profit research institute whose legal status under Ontario's health information privacy law allows it to collect and analyse healthcare and demographic data, without consent, for health system evaluation and improvement. These data sets were linked using unique encoded identifiers and analysed at ICES. The study is reported in accordance with REporting of studies Conducted using Observational Routinely-collect Data (RECORD) guidelines. $^{21}$

\section{Setting}

Canada's province of Ontario has a population of 13.5 million, ${ }^{22}$ with 1.8 million smoking cigarettes daily or occasionally (1.1 million men and 700000 women). ${ }^{23}$ Medically required healthcare services are paid for by the province through the Ontario Health Insurance Plan (OHIP). The Smoking Treatment for Ontario Patients (STOP) programme delivers smoking cessation treatment at partnering healthcare organisations and is also publicly funded. Patients can enrol through either practitionerreferral or self-referral. It is a pragmatic, real-world programme in which treatment, consisting of nicotine replacement therapy for up to 26 weeks and behavioural counselling, is individually tailored. STOP is effective with $26 \%$ of patients reporting abstinence at 6-month follow-up. ${ }^{24}$ Additional details are provided in online supplemental appendix S1.

\section{Study population}

The treatment cohort initiated smoking cessation treatment with the STOP programme between 01 July 2011 and 31 December 2012. Patient-level data were previously linked to ICES data holdings using probabilistic and deterministic linkage with a $96 \%$ linkage rate. ${ }^{25}$ Ninety per cent of patients who enrolled during the study time frame consented to linkage. For any patient who enrolled more than once, data related to their first enrolment was used. A treated patient's index date was the date of enrolment. Patients accessed treatment at one of three organisation types with greater than $99 \%$ attending a primary care clinic.

The control cohort of Ontario smokers, not using STOP services, was assembled using the Canadian Community Health Survey (CCHS), that has been linked to ICES databases. The CCHS is a cross-sectional survey conducted by Statistics Canada that collects self-reported health-related data from about 130000 Canadians in every 2 -year cycle. ${ }^{26}$ It is representative of approximately $98 \%$ of the Canadian population aged 12 and older residing in private households; detailed survey methodology is reported elsewhere. ${ }^{27}$ Approximately $84.7 \%$ of respondents residing outside the province of Quebec agreed to linkage of their data, with variation across survey years. ${ }^{28}$ We used three cycles of the CCHS to increase sample $\operatorname{size}^{29}{ }^{30}: 2007 / 2008$, $2009 / 2010$ and 2011/2012. For any respondent in multiple cycles, data from their most recent survey was used to better align with the time frame for the treatment cohort. A respondent's index date was the date they completed the survey. The study time frame was selected because it marked initiation of these STOP models, had linked CCHS data from which to select controls and allowed up to 5 years of follow-up time.

In both cohorts, individuals were excluded if sex was missing, they had an invalid record, they were ineligible for OHIP coverage, did not reside in Ontario at index date, had a date of death that preceded index date, were not smoking daily or occasionally, age was less than 12 or greater than 105 years or lacked a full 2-year lookback window. Additionally, individuals in the potential treatment cohort that also completed the CCHS were excluded if they reported not smoking in the survey.

Each treated individual was matched to one control individual using hard (sex and age at index \pm 2 years) and propensity score matching. The propensity score was obtained using multivariable logistic regression with the following covariates: age at index date (continuous with linear and quadratic terms), education quintile, household income quintile, number of cigarettes smoked per day at index (continuous with linear and quadratic terms), age first started smoking (continuous with linear and quadratic terms), number of Aggregated Diagnostic Groups (ADGs) categorical $(0-5,6-9,10+)$ and the rate of ED visits and rate of hospitalisations in the 2 years prior to index date. Missing values of categorical variables were coded as a distinct category and were included in the propensity score. Missing values of continuous variables were not included in the propensity score and patients were not matched. Once propensity scores were estimated, 1:1 matching was completed using a greedy algorithm with no replacement based on a calliper width of $0.2 \mathrm{SD}$ of the logit of the estimated propensity score. ${ }^{31}$

\section{Healthcare service utilisation outcomes}

The primary outcomes were the rate of outpatient visits, rate of ED visits and rate of all-cause hospital admissions. For each outcome, every individual could experience multiple occurrences throughout their observation period. Times to each occurrence were measured in years from index date until 31 March 2017, death or loss of OHIP eligibility, whichever occurred first. Online supplemental table S1 describes the derivation of outcome variables.

\section{Baseline characteristics}

The following self-reported descriptive characteristics were measured at index in the treatment programme intake data or CCHS survey: frequency of smoking, number of cigarettes smoked per day and age first tried smoking. Duration of smoking was calculated using an individual's age at index, from ICES data sets, and age of smoking initiation, from STOP and CCHS surveys.

Additional individual-level characteristics measured at index were derived via linkage to ICES data sets: age at index, sex and migrant status. The following prevalent comorbidities were obtained from existing ICES-derived data sets built by applying standardised algorithms: diabetes, hypertension, COPD, asthma, congestive heart failure and myocardial infarction. Ecologicallevel measures of neighbourhood educational, employment and income quintiles, and rurality were estimated using data from the 2006 Canadian census ${ }^{32}$ and were applied to individuals according to the smallest geographical census area in which they resided at index. Prior healthcare utilisation, and comorbidity burden derived from ADG scores, were estimated using a 2-year lookback window from index date. The Johns Hopkins ACG® System Aggregated Diagnosis Groups (Version 10) provide a numeric method for grouping diagnostic codes similar in severity and likelihood of persistence. They have previously been validated for use in the adult Ontario population. ${ }^{33}$ Online supplemental table S1 describes derivation of the baseline characteristic variables. 


\section{Statistical analyses}

Distributions of baseline characteristics were reported using frequencies and percentages for categorical measures and mean and SD for continuous measures. Balance between treated and control groups was assessed using standardised mean differences (SMD), where a SMD of greater than $10 \%{ }^{34}$ implies a meaningful imbalance. Initial crude analyses were conducted by calculating the total number of ED visits, outpatient visits and hospital admissions, and corresponding crude rates (per personyear) with CIs for rates generated under Poisson assumptions. ${ }^{35}$ Based on a recurrent event and counting process framework, for each outcome, the non-parametric mean cumulative function approach was used to illustrate the mean cumulative number of events as a function of time, along with $95 \%$ CIs. ${ }^{36}$

Multivariable Andersen-Gill (AG) recurrent event regression models were implemented on our matched cohort to examine the association between exposure to smoking cessation treatment and the rate of each outcome. ${ }^{37-39}$ Attained age was used as the time scale. For each outcome, the event times for an individual were the times from their index date to the date of each occurrence. Individuals were right-censored at the end of their observation window. A robust sandwich variance estimation approach was used to account for the matched design. As decided a priori, characteristics that remained unbalanced in our matched cohort at baseline between treated and control groups were included as covariates in multivariable AG regression models to account for possible confounding. Interactions with treatment (our main exposure) and comorbidities (COPD and hypertension) were to the smoking cessation treatment and outcome rates varied by presence of comorbidity.

All analyses discussed above were conducted on the overall matched cohort and stratified by sex. Analyses were performed using the SAS Enterprise Guide V.7.12 (2016, SAS Institute). Statistical tests were two-sided; an alpha of less than 0.05 was considered statistically significant.

\section{RESULTS}

Derivation and baseline characteristics by cohort

Between 01 July 2011 and 31 December 2012, 13561 Ontario had data linked to ICES data holdings. After applying the exclusion criteria described above, there were 12965 individuals in the potential treatment cohort available for matching. Of the 19 771 CCHS respondents who were smokers, 19260 were in the potential control cohort and available to serve as matches (see online supplemental figure S1).

Prior to matching, the potential treatment and control cohorts were unbalanced on several demographic characteristics: the potential treatment cohort smoked more, had a greater number of comorbidities and a higher rate of prior healthcare utilisation (see online supplemental tables S2 and S3). Of the 12965 individuals in the potential treatment cohort, 9951 were matched to a control smoker. After matching, the majority of baseline characteristics became well matched (SMD <0.1); differences remained in smoking frequency and comorbidities (see table 1 and online supplemental table S4). The median follow-up time in the treatment cohort and control cohorts were 4.8 and 6.1 years, respectively.

\section{Healthcare service use during follow-up}

Of the 9951 individuals in the treatment cohort, 9793 (98.4\%), 7944 (79.8\%) and 3499 (35.2\%) had at least one outpatient visit, also examined to determine if the association between exposure smokers used the smoking cessation treatment programme and

Table 1 Baseline characteristics and prior healthcare service use of matched treatment and control cohorts

\begin{tabular}{|c|c|c|c|}
\hline & $\begin{array}{l}\text { Treatment } \\
\text { cohort } \\
(\mathrm{n}=9951)\end{array}$ & $\begin{array}{l}\text { Control cohort } \\
(n=9951)\end{array}$ & SMD \\
\hline \multicolumn{4}{|l|}{$\begin{array}{l}\text { Sociodemographic } \\
\text { characteristics }\end{array}$} \\
\hline Age, mean $\pm S D$ & $48.96 \pm 14.18$ & $48.98 \pm 14.17$ & 0 \\
\hline \multicolumn{4}{|l|}{ Sex } \\
\hline Female & $5257(52.8)$ & $5257(52.8)$ & 0 \\
\hline Male & 4694 (47.2) & $4694(47.2)$ & 0 \\
\hline \multicolumn{4}{|l|}{ Education quintile } \\
\hline Missing & $556(5.6)$ & $541(5.4)$ & 0.01 \\
\hline Q1 (lowest) & $690(6.9)$ & $661(6.6)$ & 0.01 \\
\hline Q2 & 1485 (14.9) & 1461 (14.7) & 0.01 \\
\hline Q3 & $1989(20)$ & 1977 (19.9) & 0 \\
\hline Q4 & $2523(25.4)$ & 2548 (25.6) & 0.01 \\
\hline Q5 (highest) & $2708(27.2)$ & $2763(27.8)$ & 0.01 \\
\hline \multicolumn{4}{|l|}{ Employment quintile } \\
\hline Missing & $556(5.6)$ & $541(5.4)$ & 0.01 \\
\hline Q1 (lowest) & $2196(22.1)$ & $2234(22.5)$ & 0.01 \\
\hline Q2 & $2013(20.2)$ & 1876 (18.9) & 0.03 \\
\hline Q3 & $1787(18)$ & 1915 (19.2) & 0.03 \\
\hline Q4 & 1745 (17.5) & 1746 (17.5) & 0 \\
\hline Q5 (highest) & 1654 (16.6) & 1639 (16.5) & 0 \\
\hline \multicolumn{4}{|l|}{$\begin{array}{l}\text { Rurality + neighbourhood } \\
\text { income quintile }\end{array}$} \\
\hline Missing & $19(0.2)$ & $19(0.2)$ & 0 \\
\hline Rural & $2381(23.9)$ & $2383(23.9)$ & 0 \\
\hline Urban Q1 (lowest) & $2196(22.1)$ & 2166 (21.8) & 0.01 \\
\hline Urban Q2 & 1579 (15.9) & $1597(16)$ & 0 \\
\hline Urban Q3 & $1431(14.4)$ & 1477 (14.8) & 0.01 \\
\hline Urban Q4 & 1336 (13.4) & $1321(13.3)$ & 0 \\
\hline Urban Q5 (highest) & 1009 (10.1) & $988(9.9)$ & 0.01 \\
\hline \multicolumn{4}{|l|}{ Migrant status } \\
\hline Immigrant* & $262(2.6)$ & $267(2.7)$ & 0 \\
\hline Non-immigrant & 9689 (97.4) & $9684(97.3)$ & 0 \\
\hline \multicolumn{4}{|l|}{ Smoking characteristics } \\
\hline \multicolumn{4}{|l|}{ Frequency of smoking } \\
\hline Daily & 9745 (97.9) & $9133(91.8)$ & 0.28 \\
\hline Occasional & $206(2.1)$ & $818(8.2)$ & 0.28 \\
\hline Cigarettes per day, mean \pm SD & $17.82 \pm 9.77$ & $17.56 \pm 9.56$ & 0.03 \\
\hline $\begin{array}{l}\text { Age first tried smoking, } \\
\text { mean } \pm S D\end{array}$ & $15.82 \pm 4.81$ & $15.69 \pm 4.67$ & 0.03 \\
\hline $\begin{array}{l}\text { Duration smoking (years), } \\
\text { mean } \pm S D\end{array}$ & $33.14 \pm 14.41$ & $33.29 \pm 14.20$ & 0.01 \\
\hline \multicolumn{4}{|l|}{ Health comorbidities } \\
\hline \multicolumn{4}{|l|}{ Prevalent comorbidities } \\
\hline COPD & $2985(30)$ & $2018(20.3)$ & 0.23 \\
\hline Hypertension & $2863(28.8)$ & $2694(27.1)$ & 0.04 \\
\hline Diabetes & $1515(15.2)$ & $1146(11.5)$ & 0.11 \\
\hline Asthma & $1882(18.9)$ & $1474(14.8)$ & 0.11 \\
\hline Cancer & $448(4.5)$ & $400(4)$ & 0.02 \\
\hline Myocardial infarction & $332(3.3)$ & $248(2.5)$ & 0.05 \\
\hline Congestive heart failure & $235(2.4)$ & $193(1.9)$ & 0.03 \\
\hline No. ADG comorbidities, mean \pm SD & $5.84 \pm 3.43$ & $5.45 \pm 3.63$ & 0.11 \\
\hline $0-5$ & $5149(51.7)$ & $5177(52)$ & 0.01 \\
\hline $6-9$ & $3314(33.3)$ & 3355 (33.7) & 0.01 \\
\hline \multirow[t]{2}{*}{$10+$} & $1488(15)$ & $1419(14.3)$ & 0.02 \\
\hline & & & Continued \\
\hline
\end{tabular}

Baliunas D, et al. Tob Control 2021;0:1-8. doi:10.1136/tobaccocontrol-2021-056522 


\begin{tabular}{llll}
\hline Table 1 Continued & & & \\
\hline & $\begin{array}{l}\text { Treatment } \\
\text { cohort } \\
(\mathbf{n}=9951)\end{array}$ & $\begin{array}{l}\text { Control cohort } \\
(\mathbf{n}=9951)\end{array}$ & SMD \\
\hline $\begin{array}{l}\text { Rate of healthcare service } \\
\text { use ppy }\end{array}$ & & & \\
\hline $\begin{array}{l}\text { Outpatient visits (mean } \pm S D) \\
\text { ED visits (mean } \pm S D)\end{array}$ & $6.61 \pm 8.62$ & $6.16 \pm 7.64$ & 0.06 \\
\hline Hospitalisations (mean \pm SD) & $0.13 \pm 0.38$ & $0.12 \pm 0.37$ & 0.02 \\
\hline
\end{tabular}

Number (\%) are reported unless otherwise noted.

*Includes immigrants and refugees.

tDuring 2-year period up to index date.

ADG, Aggregated Diagnostic Groups; COPD, chronic obstructive pulmonary

disease; ED, emergency department; ppy, per person year; Q, quintile; SMD,

standardised mean difference.

ED visit or hospitalisation, respectively. Similarly, of the 9951 individuals in the control cohort, 9606 (96.5\%), 7844 (79.8\%) and $3815(38.3 \%)$ had at least one outpatient visit, ED visit or hospitalisation, respectively. Table 2 shows the crude rates of outpatient visits, ED visits and hospitalisations in the matched treatment and control cohorts, overall and by sex. Patterns were similar for outpatient and ED visits: the rates were higher in the treatment cohort than in the control cohort. This was observed in the overall and sex-stratified cohorts. Within treatment and control cohorts, crude rates were higher in women than in men. For hospitalisations, the overall pattern observed was similar to that for outpatient and ED visits, but with differences attenuated. These findings are depicted visually in figure 1 , which plots the estimated mean cumulative number of outpatient visits, ED visits and hospitalisations during follow-up (and 95\% CIs) for the treatment and matched control cohorts, both overall and by sex. Point estimates at 2 and 5 years are provided; for example, 5 years after index date the cumulative number of outpatient visits in the overall cohorts were 35.02 and 31.16 among the treatment and control cohorts, respectively.

\section{Adjusted association between smoking cessation treatment and healthcare service use}

Compared with matched controls, after controlling for potential confounders, patients in the overall treatment cohort had

Table 2 Crude rates and adjusted associations between smoking cessation treatment and healthcare service use outcomes in Ontario, Canada, between 2011 and 2017, in matched treatment and control cohorts, overall and stratified by sex

\begin{tabular}{|c|c|c|c|c|}
\hline \multirow[b]{2}{*}{ Outcome } & \multirow[b]{2}{*}{ Sex } & \multicolumn{2}{|c|}{$\begin{array}{l}\text { Unadjusted } \\
\text { mean } \pm \text { SD rate ppy }\end{array}$} & \multirow[b]{2}{*}{$\begin{array}{l}\text { Adjusted rate ratio } \\
(95 \% \mathrm{Cl})\end{array}$} \\
\hline & & $\begin{array}{l}\text { Treatment } \\
\text { cohort }\end{array}$ & $\begin{array}{l}\text { Control } \\
\text { cohort }\end{array}$ & \\
\hline \multirow[t]{3}{*}{ Outpatient visits } & Overall & $7.52 \pm 10.26$ & $6.73 \pm 8.42$ & $1.10(1.06$ to 1.14$)$ \\
\hline & Female & $8.03 \pm 10.06$ & $7.44 \pm 8.40$ & 1.08 (1.03 to 1.12$)$ \\
\hline & Male & $6.95 \pm 10.46$ & $5.93 \pm 8.38$ & $1.13(1.07$ to 1.19$)$ \\
\hline \multirow[t]{3}{*}{ ED visits } & Overall & $1.03 \pm 1.78$ & $0.88 \pm 1.67$ & $1.08(1.03$ to 1.13$)$ \\
\hline & Female & $1.06 \pm 1.77$ & $0.95 \pm 1.72$ & 1.05 (0.98 to 1.12$)$ \\
\hline & Male & $0.99 \pm 1.80$ & $0.80 \pm 1.60$ & $1.13(1.05$ to 1.20$)$ \\
\hline \multirow[t]{3}{*}{ Hospitalisations } & Overall & $0.23 \pm 0.81$ & $0.21 \pm 0.68$ & 1.09 (1.02 to 1.18$)$ \\
\hline & Female & $0.23 \pm 0.84$ & $0.21 \pm 0.73$ & 1.09 (1.00 to 1.19$)$ \\
\hline & Male & $0.24 \pm 0.78$ & $0.20 \pm 0.63$ & 1.10 (0.98 to 1.24$)$ \\
\hline
\end{tabular}

Bolded rate ratios are significant at $p<0.05$.

$E D$, emergency department; ppy, per person year. significantly greater rates of each of the three healthcare service use outcomes. The magnitude of the positive associations was modest. Stratified by sex, a positive association between smoking cessation treatment and healthcare service use was observed for ED visits among men only, and for outpatient visits among women and among men, but the magnitude of association was greater in men. Findings were inconclusive as to whether there was an association observed for hospitalisations among women or among men (see table 2).

Effect modification of the association between smoking cessation treatment and healthcare service use by prevalent comorbidity was found for outpatient visits in the overall cohort $(p=0.006)$, with no difference in rates versus controls in patients with prevalent hypertension (figure 2). These effects were primarily driven by differences in women, among whom rates were significantly greater versus controls in patients with neither hypertension nor COPD. In patients with either one or both conditions, findings were inconclusive as to whether or not there was a difference between treatment and control cohorts. Statistically significant effect modification was also found in the overall cohort for hospitalisations, with greater rates versus controls in patients with neither prevalent hypertension nor COPD, and in patients with COPD only, than among patients with hypertension only or both conditions; $p=0.05$ ). The complete multivariable regression estimates are available in online supplemental tables S5-S13.

\section{DISCUSSION}

In this study of 19902 matched smokers, we found a slightly greater rate of outpatient visits, ED visits and hospitalisations among smokers who had accessed the smoking cessation treatment programme compared with smokers who did not. In analyses stratified by sex, the increased rate of outpatient visits was observed among men and women, while the increased rate of ED visits was restricted to men only. The increased rate of hospitalisations was observed in the overall cohort but not when stratified by sex.

The difference in healthcare service use between the intervention and matched control groups was greater among those patients who did not have pre-existing comorbid conditions-and lesser among patients who did. The implication is that for patients who are already engaged with the healthcare system for the diagnosis and treatment of chronic disease, the addition of smoking cessation treatment has less impact on the subsequent rate of healthcare use. This is an important finding because COPD and hypertension were common in the matched cohorts and are common in people who smoke generally.

Our findings contrast with prior studies that showed a decrease in healthcare service use associated with smoking cessation treatment. ${ }^{8-1214}$ A possible explanation for the contradictory findings may lie with differences in treatment setting, patient population and healthcare service outcome measures in our and most prior studies. Patients in primary care settings are less likely to have severe comorbidities requiring hospitalisation; indeed $83.2 \%$ of individuals in our matched treatment cohort had not been hospitalised in the 2 years prior to index date. By focusing on hospitalised patients, and re-hospitalisation outcome measures, previous investigations have focused on narrower populations, and possibly ones likely to benefit from an intervention in the short-term during a teachable moment. ${ }^{13}$ In the singular prior study ${ }^{14}$ that also had a general population of smoking cessation treatment users, the likelihoods of hospitalisations for two indications (myocardial infarction and atherosclerosis) were 

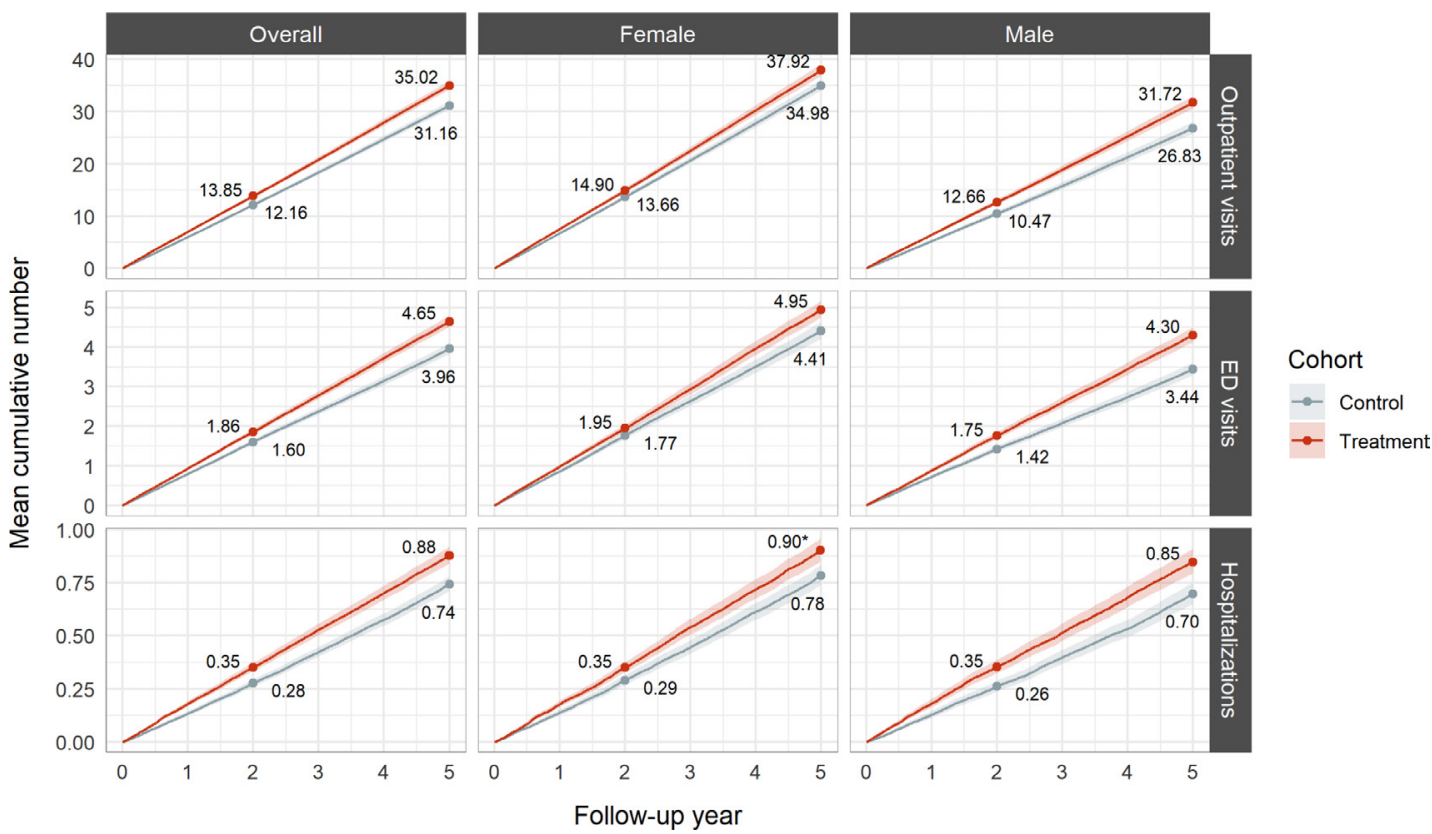

Figure 1 Estimated mean cumulative number of outpatient visits, emergency department visits and hospitalisations in Ontario, Canada, between 2011 and 2017, in matched treatment and control cohorts, overall and stratified by sex. *Mean cumulative number of hospitalisations for women in the Smoking Treatment for Ontario Patients cohort at year 4.99. ED, emergency department.

decreased, but no decrease or increase for 13 other cause-specific hospitalisations or all-cause hospitalisations were observed. The prior literature, with its dearth of directly relevant studies, does not provide a strong context into which to place our results. The related literature, however, linking smoking status itself with healthcare service utilisation is relevant. Relative to never smokers, current smokers have greater healthcare service utilisation in most, ${ }^{40-48}$ but not all, ${ }^{414249}$ analyses. While there is some evidence that healthcare service use is also lower among former smokers relative to current smokers, ${ }^{40} 43$ in various analyses smoking cessation is associated with a short-term increase in usage that remains above that of, similar to, or below that of, current smokers, ${ }^{41-434647}$ or is not associated with any increase or decrease. ${ }^{414350}$ These findings provide conflicting and indirect evidence that smoking cessation may reduce healthcare service use but that reductions may not be realised for some time.

In our study, the rate of healthcare service use in the 2 years prior to the index date was similar in the matched cohorts. Since the number of patients who quit smoking is likely greater in the treatment cohort than the control cohort, ${ }^{13245152}$ if quitting smoking results in decreased healthcare service use then it follows that healthcare service use should be lower on average in the treatment cohort than the control cohort. As that was not observed, these findings suggest that, in the population of Ontarian smokers, either the beneficial effect of smoking cessation treatment on healthcare service use among those patients who achieve abstinence is outweighed by the lack of such effect among the majority of patients who do not achieve abstinence, or there is no such beneficial effect during the first 5 years following initiation of smoking cessation treatment.

Further research should build on these findings. It is unclear in the observed increased healthcare service use is a positive or negative consequence of smoking cessation treatment and what mechanisms underly the observed association. Our study lacked longitudinal measures of smoking status or complex smoking cessation trajectories due to the absence of such data in routinely collected administrative healthcare data. Longitudinal studies of smokers, if linked to administrative healthcare data and of sufficient size to have robust numbers of treatment seeking smokers, could help address these important gaps. Additionally, patients in Ontario do not incur personal costs (eg, service fees or copays) to access ED, outpatient or hospitalisation services; further research is warranted to assess the impact of smoking cessation treatment in jurisdictions where these barriers to healthcare service use exist.

Assessing the healthcare system implications associated with uptake of available smoking cessation treatment services is important for tobacco control experts and healthcare system planners internationally. Relatively few smokers who attempt to quit use available smoking cessation resources. ${ }^{53}$ However, tobacco control policies, such as increased taxation, antismoking media campaigns and comprehensive smoke-free policies, increase the demand for tobacco dependence treatment and therefore, continued capacity building and adoption of FCTC guidelines may both increase interest in smoking cessation treatment and provide guidelines for implementation in primary care settings. ${ }^{53}$

Strengths of this study include the use of a non-treatment seeking control group. Such a control group cannot be derived from typical administrative healthcare data and was possible due to the prior linkage of very large population based health survey data. Additionally, use of a concurrent control group allowed for avoidance of temporal differences that can impact results when a pre-post design is used. Lastly, all outcomes in both treatment and control groups were ascertained identically using healthcare administrative databases therefore bias resulting from differential missing data are unlikely.

This study also has limitations. First, the exposure, which necessarily requires both motivation to quit smoking and a willingness to engage with smoking cessation treatment, cannot be randomised. Although we accounted for a range of factors through hard and propensity score matching and adjustment for potential confounders, there is potential for unmeasured or residual confounding. Second, the statistical analyses necessarily 


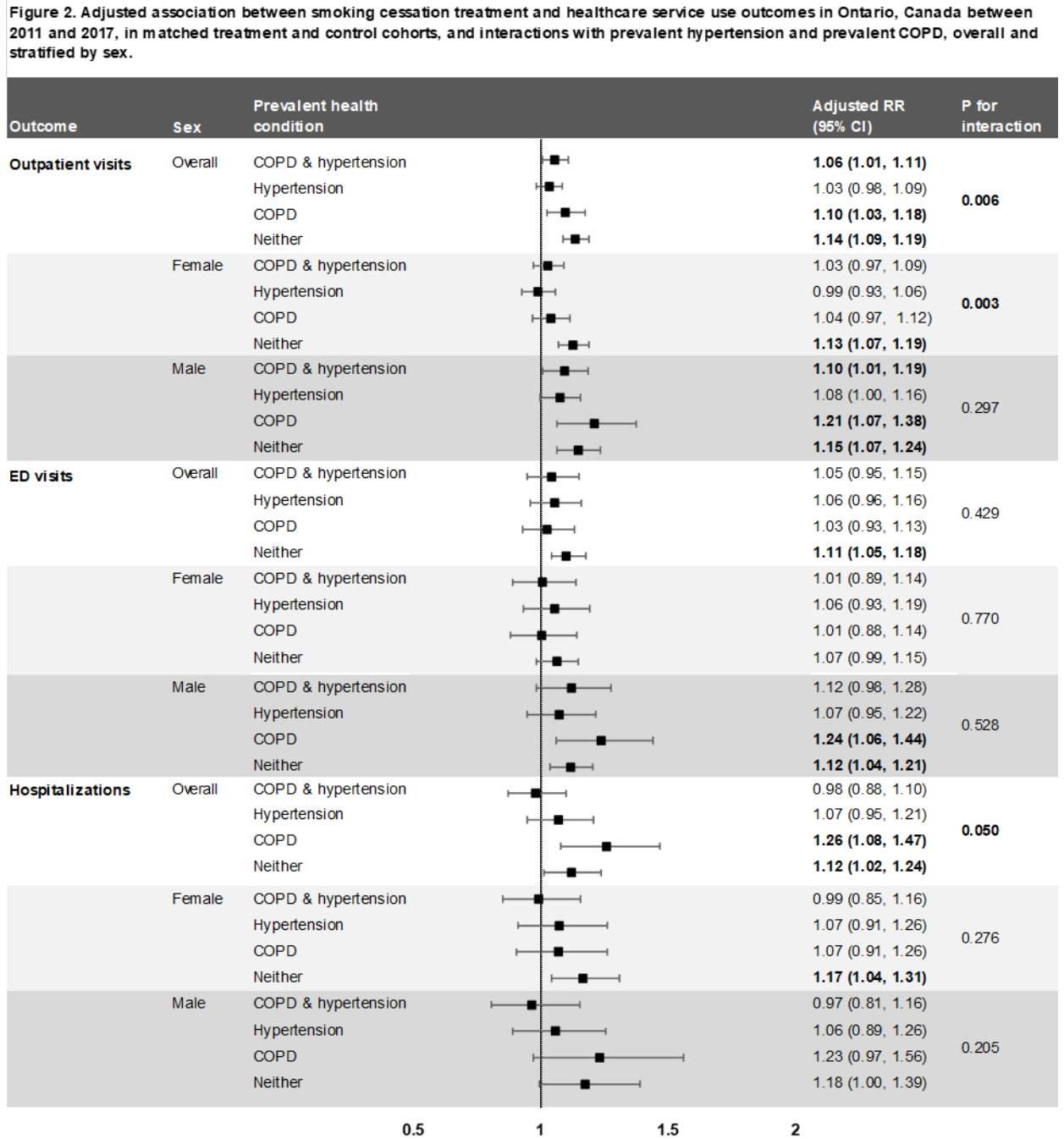

Figure 2 Adjusted association between smoking cessation treatment and healthcare service use outcomes in Ontario, Canada, between 2011 and 2017, in matched treatment and control cohorts, overall and stratified by sex. Bolded RRs are significant at $p<0.05$. COPD, chronic obstructive pulmonary disease; ED, emergency department; RR, rate ratio.

were restricted to treatment patients who were successfully matched to a control, thus including the majority of, but not all, patients. We combined cycles of the CCHS in order to increase the number of potential matches, but residual differences may have occurred affecting generalisability. Third, the length of follow-up in our study is insufficient to ascertain any long-term impacts of smoking cessation treatment on healthcare service utilisation.

\section{CONCLUSIONS}

Primary care-based smoking cessation treatment in Ontario, Canada, was associated with a small but significant increase in the rate of all-cause outpatient visits, ED visits and hospitalisations, but there was significant heterogeneity in some outcomes depending on sex and the presence of comorbid COPD and hypertension.

\section{Author affiliations}

${ }^{1}$ School of Public Health, The University of Queensland, Herston, Queensland, Australia

${ }^{2}$ Clinical Research Addictions, Centre for Addiction and Mental Health, Toronto, Ontario, Canada

${ }^{3}$ Dalla Lana School of Public Health, University of Toronto, Toronto, Ontario, Canada
${ }^{4}$ Nicotine Dependence Service, Centre for Addiction and Mental Health, Toronto, Ontario, Canada

${ }^{5}$ Department of Psychiatry, Centre for Addiction and Mental Health, Toronto, Ontario, Canada

${ }^{6}$ Department of Family and Community Medicine, University of Toronto, Toronto, Ontario, Canada

${ }^{7}$ Centre for Health Economics and Hull York Medical School, University of York, York, UK

${ }^{8}$ Institute for Mental Health Policy Research, Centre for Addiction and Mental Health, Toronto, Ontario, Canada

${ }^{9}$ ICES, Toronto, Ontario, Canada

${ }^{10}$ Institute of Health Policy, Management and Evaluation, University of Toronto,

Toronto, Ontario, Canada

${ }^{11}$ Centre for Addiction and Mental Health, Toronto, Ontario, Canada

${ }^{12}$ Department of Pharmacology and Toxicology, University of Toronto Faculty of Medicine, Toronto, Ontario, Canada

${ }^{13}$ Division of Biostatistics, University of Toronto, Toronto, Ontario, Canada

Twitter Peter Selby @drpselby, Claire de Oliveira @clairede0 and Laurie Zawertailo @lazawert

Acknowledgements We thank Kinwah Fung for methodological support and Sabrina Voci, Anna Ivanova and Evgenia Gatov for project support. Parts of this material are based on data and/or information compiled and provided by the Canadian Institute for Health Information (CIHI), the Immigration, Refugees and Citizenship Canada (IRCC), the Office of the Registrar General (ORG) and Cancer Care Ontario (CCO). However, the analyses, conclusions, opinions and statements 
expressed herein are those of the authors and not necessarily those of $\mathrm{CIHI}, \mathrm{IRCC}$, ORG, CCO or the Ontario Ministry of Health.

Contributors DB, PS, CdO, PK, LR, LZ and RS contributed to conceptualisation and study design. DB wrote the original draft manuscript and prepared the final version. RS contributed to writing. LF conducted the data analysis. All authors contributed to data interpretation and manuscript review. All authors gave final approval of the version to be published.

Funding This work was funded by a Canadian Institutes for Health Research project grant awarded to DB (PI), PS, CdO, PK, LR, LZ and RS (Co-Is).

Competing interests $\mathrm{DB}$ reports receiving grant funding in the past 5 years from Pfizer, Ontario Ministry of Health and Long-Term Care, Canadian Institutes of Health Research (CIHR) and the Canadian Cancer Society Research Institute (CCSRI). PS reports receiving funding in the past 3 years from CCSRI, CIHR, Canadian Partnership Against Cancer, Centre for Addiction and Mental Health (CAMH), Health Canada, Medical Psychiatry Alliance, Ontario Ministry of Health and Long-Term Care, Ontario Neurotrauma Foundation and the Public Health Agency of Canada. PS also reports funding from the following commercial organisations: Patient-Centred Outcome Research Institute and Pfizer. PS has received honoraria in the past 3 years from University of Ottawa Heart Institute, Royal College of Physicians and Surgeons of Canada, Royal Victoria Regional Health Centre, Department of Family and Community Medicine at the University of Toronto, Northern Ontario School of Medicine, Canadian Partnership Against Cancer, Battle River Treaty 6 Healthcare, Lung Association of Nova Scotia, Exchange Summit, Toronto Public Health, Ontario Association of Public Health Dentistry and ECHO. PS has been retained as an expert witness by the Ontario and New Brunswick provincial governments in litigation against the tobacco industry. PS was a member and co-chaired the Ministry of Health's Ontario Smoke Free Strategy cessation subcommittee. Through an open tender process, Johnson \& Johnson, Novartis and Pfizer are vendors of record for providing free/discounted smoking cessation pharmacotherapy for research studies in which PS and/or LZ are principal or co-investigator. CdO reports receiving grant funding in the past 5 years from CIHR, University of Toronto, Medical Research Council, National Institutes of Health, CAMH, Alberta Innovates, Ontario Ministry of Health and Long-Term Care, Canadian Centre for Applied Research in Cancer Control and Ontario Mental Health Foundation. PK reports receiving grant funding in the past 5 years from CIHR and the Ontario Ministry of Health and Long-Term Care. LR reports receiving grant funding in the past 5 years from CIHR, New Frontiers in Research Fund, Canada Research Chairs and the Connaught Foundation. LZ reports receiving grant funding in the past 5 years from Pfizer, Ontario Ministry of Health and

What this paper adds

What is already known on this subject

- Hospital-based smoking cessation programmes, an intervention that takes place during a teachable moment, can lower subsequent hospital re-admission rates.

What important gaps in knowledge exist on this topic

- The translation of the clinical effectiveness of primarycare based smoking cessation programmes, which serve patients less likely to have severe comorbidities requiring hospitalisation, on healthcare service use using real-world evidence has received limited attention in the literature.

- Only one study has examined healthcare service use among a broad general patient base of smokers that accessed smoking cessation treatment. A decrease in hospitalisations for two indications was observed, but no decrease or increase for 13 other cause-specific hospitalisations or all-cause hospitalisations.

- The impact on other healthcare service types has not been assessed.

\section{What this paper adds}

- Primary care-based smoking cessation treatment was associated with a small increase in the rate of all-cause outpatient visits, ED visits and hospitalisations

- For patients who are already engaged with the healthcare system for the diagnosis and treatment of chronic disease, the addition of smoking cessation treatment had less impact on the subsequent rate of healthcare use.
Long-Term Care, Health Canada, CIHR and CCSRI. LZ also received honoraria and travel funds from Pfizer and University of Ottawa Heart Institute. RS reports receiving funding in the past 5 years from CIHR, Terry Fox Research Institute, Garron Family Cancer Centre and Sick Kids Foundation, Canadian Society of Colon and Rectal Surgeons, Sunnybrook Foundation, Pediatric Oncology Group of Ontario, Ontario Institute for Cancer Research, PSI Foundation, C17 Research Network, Cancer Care Ontario, Canadian Centre for Applied Research in Cancer Control, Canadian Breast Cancer Foundation, Sunnybrook AFP Innovation Fund, CCSRI, Ministry of Health and Long-Term Care and the Ontario Medical Association. PS, LZ, PK, DB and CdO have been employed by CAMH in the past 36 months; results of this study may impact whether CAMH continues to receive funding from the Ministry of Health to administer the STOP programme. No other author has competing interests to declare.

Patient consent for publication Not required.

Ethics approval The Centre for Addiction and Mental Health Research Ethics Board approved this study (\#110/2019), data linkage (\#027/2016) and smoking cessation treatment models (\#058/2011,\#154/2012), and patients provided written informed consent.

Provenance and peer review Not commissioned; externally peer reviewed.

Data availability statement The data set from this study, composed of STOP programme data and ICES data sets, is held securely in coded form at ICES. While data sharing agreements and privacy legislation for the province of Ontario prohibit ICES from making the data set publicly available, access may be granted to those who meet pre-specified criteria for confidential access, available at https://www. ices.on.ca/DAS. Requests to access ICES data may be submitted to ICES Data \& Analytic Services at das@ices.on.ca, with information available at https://www.ices. on.ca/DAS/Submitting-your-request. One of the authors (LF) had access to the linked databases and conducted all analyses.

Open access This is an open access article distributed in accordance with the Creative Commons Attribution Non Commercial (CC BY-NC 4.0) license, which permits others to distribute, remix, adapt, build upon this work non-commercially, and license their derivative works on different terms, provided the original work is properly cited, appropriate credit is given, any changes made indicated, and the use is non-commercial. See: http://creativecommons.org/licenses/by-nc/4.0/.

\section{ORCID iDs}

Dolly Baliunas http://orcid.org/0000-0001-5685-0715

Peter Selby http://orcid.org/0000-0001-5401-2996

Claire de Oliveira http://orcid.org/0000-0003-3961-6008

Laurie Zawertailo http://orcid.org/0000-0002-4547-1565

\section{REFERENCES}

1 Reitsma MB, Fullman N, Ng M, et al. Smoking prevalence and attributable disease burden in 195 countries and territories, 1990-2015: a systematic analysis from the global burden of disease study 2015. The Lancet 2017;389:1885-906.

2 Ekpu VU, Brown AK. The economic impact of smoking and of reducing smoking prevalence: review of evidence. Tob Use Insights 2015;8:TUI.S15628-35.

3 Scholar WHOJG. Who report on the global tobacco epidemic, 2019. Geneva World Health Organization; 2019; 2019.

4 Stead LF, Koilpillai P, Fanshawe TR, et al. Combined pharmacotherapy and behavioural interventions for smoking cessation. Cochrane Database Syst Rev 2016;3:CD008286

5 Hartmann-Boyce J, Chepkin SC, Ye W, et al. Nicotine replacement therapy versus control for smoking cessation. Cochrane Database Syst Rev 2018;5:CD000146.

6 Cahill K, Stevens S, Perera R, et al. Pharmacological interventions for smoking cessation: an overview and network meta-analysis. Cochrane Database Syst Rev 2013;5:CD009329.

7 Lee LJ, Li Q, Bruno M, et al. Healthcare costs of smokers using varenicline versus Nicotine-Replacement therapy patch in the United States: evidence from real-world practice. Adv Ther 2019;36:365-80

8 Mohiuddin SM, Mooss AN, Hunter CB, et al. Intensive smoking cessation intervention reduces mortality in high-risk smokers with cardiovascular disease. Chest 2007;131:446-52.

9 Prochaska JJ, Hall SE, Delucchi K, et al. Efficacy of initiating tobacco dependence treatment in inpatient psychiatry: a randomized controlled trial. Am J Public Health 2014; 104:1557-65.

10 Cartmell KB, Dooley M, Mueller M, et al. Effect of an evidence-based inpatient tobacco dependence treatment service on 30-, 90-, and 180-Day Hospital readmission rates. Med Care 2018;56:358-63.

11 van den Broek-Altenburg EM, Atherly AJ. The effect of an inpatient smoking cessation treatment program on hospital readmissions and length of stay. J Hosp Med 2017; 12:880-5.

12 Mullen KA, Manuel DG, Hawken SJ, et al. Effectiveness of a hospital-initiated smoking cessation programme: 2-year health and healthcare outcomes. Tob Control 2017;26:293-9. 
13 Abuse S, MHSA US, OotS G. Smoking cessation: a report of the surgeon General 2020.

14 Land T, Rigotti NA, Levy DE, et al. A longitudinal study of Medicaid coverage for tobacco dependence treatments in Massachusetts and associated decreases in hospitalizations for cardiovascular disease. PLoS Med 2010;7:e1000375.

15 Gershon AS, Guan J, Victor JC, et al. Quantifying health services use for chronic obstructive pulmonary disease. Am J Respir Crit Care Med 2013;187:596-601.

16 Muggah E, Graves E, Bennett C, et al. The impact of multiple chronic diseases on ambulatory care use; a population based study in Ontario, Canada. BMC Health Serv Res 2012;12:452.

17 Iron K, Lu H, Manuel D, et al. Using linked health administrative data to assess the clinical and healthcare system impact of chronic diseases in Ontario. Hcq 2011;14:23-7.

18 Kirkland EB, Heincelman M, Bishu KG, et al. Trends in healthcare expenditures among US adults with hypertension: national estimates, 2003-2014. J Am Heart Assoc 2018;7.

19 Weaver CG, Clement FM, Campbell NRC, et al. Healthcare costs attributable to hypertension: Canadian population-based cohort study. Hypertension 2015;66:502-8.

20 Dresler CM, León ME, Straif K, et al. Reversal of risk upon quitting smoking. The Lancet 2006;368:348-9.

21 Benchimol El, Smeeth L, Guttmann A, et al. The reporting of studies conducted using observational Routinely-collected health data (record) statement. PLoS Med 2015;12:e1001885.

22 Census profile, 2016 Censurs: Ontario [Province] and Canada [Country]. Available: https://www12.statcan.gc.ca/census-recensement/2016/dp-pd/prof/details/Page. $\mathrm{cfm}$ ? Lang $=$ E\&Geo1 $=$ PR\&Code $1=35 \& G e 02=\&$ Code2 $=\&$ Data $=$ Count $\&$ SearchText $=$ Ontario\&Sear

23 Statistics Canada. Table 13-10-0096-01. health characteristics, annual estimates.

24 Veldhuizen S, Zawertailo L, Ivanova A, et al. Seasonal variation in demand for smoking cessation treatment and clinical outcomes. Nicotine Tob Res 2020. doi:10.1093/ntr/ ntaa214. [Epub ahead of print: 21 Oct 2020].

25 Baliunas D, Zawertailo L, Voci S, et al. Variability in patient sociodemographics, clinical characteristics, and healthcare service utilization among 107,302 treatment seeking smokers in Ontario: a cross-sectional comparison. PLoS One 2020;15:e0235709.

26 Statistics Canada. Canadian community health survey annual component (CCHS). Available: http://www23.statcan.gc.ca/imdb/p2SV.pl? Function $1 / 4$ getSurvey\&ld $1 / 4144170$ [Accessed 01 Mar 2018].

27 Béland Y. Canadian community health survey--methodological overview. Health Rep 2002;13:9-14.

28 Statistics Canada. Canadian community health survey data (2000 to 2011) linked to the discharge Abstract database (1999/2000-2012/2013). Available: https://www. statscan.gc.ca/eng/rdc/cencchs-dad

29 Manuel DG, Perez R, Sanmartin C, et al. Measuring burden of unhealthy behaviours using a multivariable predictive approach: life expectancy lost in Canada attributable to smoking, alcohol, physical inactivity, and diet. PLoS Med 2016;13:e1002082.

30 Thomas S, Wannell B. Combining cycles of the Canadian community health survey. Health Rep 2009;20:53-8.

31 Austin PC. An introduction to propensity score methods for reducing the effects of confounding in observational studies. Multivariate Behav Res 2011;46:399-424.

32 Statistics Canada. Census of population 2006.

33 Austin PC, van Walraven C, Wodchis WP, et al. Using the Johns Hopkins aggregated diagnosis groups (ADGS) to predict mortality in a general adult population cohort in Ontario, Canada. Med Care 2011;49:932-9.
34 Normand ST, Landrum MB, Guadagnoli E, et al. Validating recommendations for coronary angiography following acute myocardial infarction in the elderly: a matched analysis using propensity scores. J Clin Epidemiol 2001;54:387-98.

35 Daly L. Simple SAS macros for the calculation of exact binomial and Poisson confidence limits. Comput Biol Med 1992;22:351-61.

36 Lawless JF, Nadeau C. Some simple robust methods for the analysis of recurrent events. Technometrics 1995;37:158-68.

37 Cook RJ, Lawless JF. Analysis of repeated events. Stat Methods Med Res 2002;11:141-66

38 Twisk JWR, Smidt N, de Vente W. Applied analysis of recurrent events: a practical overview. J Epidemiol Community Health 2005;59:706-10.

39 Therneau TM, Grambsch PM. Modeling survival data: extending the COX model. New York, NY: Springer, 2000.

40 Manuel DG PR, Bennett C, Rosella LC. 900,000 days in hospital: the annual impact of smoking, alcohol, diet and physical activity on hospital use in Ontario. Toronto, ON Institute for Clinical Evaluative Sciences; 2014.

41 Kahende J, Adhikari B, Maurice E, et al. Disparities in health care utilization by smoking status - NHANES 1999-2004. Int J Environ Res Public Health 2009;6:1095-106.

42 Azagba S, Sharaf MF, Xiao Liu C. Disparities in health care utilization by smoking status in Canada. Int J Public Health 2013;58:913-25.

43 Wilkins K, Shields M, Rotermann M. Smokers' use of acute care hospitals--a prospective study. Health Rep 2009;20:75-83.

44 Woodruff SI, Conway TL, Shillington AM, et al. Cigarette smoking and subsequent hospitalization in a cohort of young U.S. navy female recruits. Nicotine Tob Res 2010;12:365-73

45 Robbins AS, Fonseca VP, Chao SY. Short term effects of cigarette smoking on hospitalisation and associated lost workdays in a young healthy population. Tob Control 2000;9:389-96

46 Østbye T, Taylor DH, Jung S-H. A longitudinal study of the effects of tobacco smoking and other modifiable risk factors on ill health in middle-aged and old Americans: results from the health and retirement study and asset and health dynamics among the oldest old survey. Prev Med 2002;34:334-45.

47 Wagner EH, Curry SJ, Grothaus L, et al. The impact of smoking and quitting on health care use. Arch Intern Med 1995;155:1789-95.

48 Izumi Y, Tsuji I, Ohkubo T, et al. Impact of smoking habit on medical care use and its costs: a prospective observation of national health insurance beneficiaries in Japan. Int J Epidemiol 2001;30:616-21.

49 Borzecki AM, Lee A, Kalman D, et al. Do poor health behaviors affect health-related quality of life and healthcare utilization among Veterans? the Veterans health study. J Ambul Care Manage 2005;28:141-56.

50 Beard E, Shahab L, Curry SJ, et al. Association between smoking cessation and short-term health-care use: results from an international prospective cohort study (ATTEMPT). Addiction 2013;108:1979-88.

51 Voci S, Zawertailo L, Baliunas D, et al. Is cannabis use associated with tobacco cessation outcome? an observational cohort study in primary care. Drug Alcohol Depend 2020;206:107756.

52 Hughes JR. Tobacco withdrawal in self-quitters. J Consult Clin Psychol 1992;60:689-97

53 US National Cancer Institute and World Health Organization. The economics of tobacco and tobacco control. National cancer Institute tobacco control monograph 21. NIH publication No. 16-CA-8029A.. Bethesda, MD; Geneva, CH Department of Health and Human Services, National Institutes of Health, National Cancer Institute; World Health Organization; 2004. 